\title{
Mengasuh Anak Usia Prasekolah Vs Anak Usia Sekolah Dasar: Manakah Yang Lebih Menimbulkan Stres Pengasuhan Pada Ibu?
}

\author{
Dewi Kumalasari ${ }^{1}$, Izmiyah Afaf Abdul Gani ${ }^{2}$ \\ ${ }^{1}$ Fakultas Psikologi \\ Universitas YARSI, Jakarta, 10510, Indonesia \\ _dewi.kumalasari@yarsi.ac.id
}

\begin{abstract}
Preschool-age and school-age are phases that have different parenting challenges, which can trigger parenting stress on mothers. This study aimed to examine the parenting stress differences between mothers of preschoolers and mothers of school-aged children. This research used a quantitative approach with a cross-sectional design. Parenting stress is measured through the Parental Stress Scale (PSS) instrument. This study involved 249 respondents who were selected through convenience sampling methods. Analysis of the different tests with the Mann Withney technique showed that there were significant differences in parenting stress from the two groups. Mothers of school-aged children are found to experience higher parenting stress than mothers of preschool-aged children. Further studies involving culture-related variables and longitudinal design are suggested.
\end{abstract}

Keyword : Mother; Parenting Stress; Preschool-aged; School-aged.

\begin{abstract}
Abstrak
Usia prasekolah dan usia sekolah dasar merupakan fase yang memiliki tantangan pengasuhan yang berbeda, yang dapat memicu stres pengasuhan pada Ibu. Penelitian ini bertujuan untuk melihat perbedaan stres pengasuhan pada Ibu yang mengasuh anak usia prasekolah dan usia sekolah dasar. Penelitian ini menggunakan pendekatan kuantitatif dengan desain cross sectional. Stres pengasuhan diukur melalui instrument Parental Stres Scale (PSS). Penelitian ini melibatkan 249 responden yang dipilih melalui metode convenience sampling. Analisis uji beda dengan teknik Mann Withney menunjukkan bahwa ada perbedaan stres pengasuhan yang signifikan dari dua kelompok tersebut. Ibu yang mengasuh anak usia sekolah ditemukan mengalami stres pengasuhan yang lebih tinggi daripada ibu yang mengasuh anak usia prasekolah. Untuk pengembangan studi, pelibatan variabel yang terkait dengan budaya dan penggunaan desain longitudinal disarankan.
\end{abstract}

Kata kunci: Ibu; Stres Pengasuhan; Usia Prasekolah; Usia Sekolah Dasar

\section{Pendahuluan}

Umumnya, ibu adalah kunci dari proses pengasuhan, khususnya saat anak berada pada masa anak-anak. Bornstein (2013) menyatakan bahwa secara umum Ibu menghabiskan $65-80 \%$ waktu lebih banyak daripada ayah dalam berinteraksi langsung dengan anak. Di Indonesia, hal ini dimungkinkan karena sistem patriarki 
yang dianut menempatkan ayah sebagai kepala keluarga yang bertugas sebagai economic provider, sedangkan ibu bertugas sebagai pengasuh anak (Bemelen, 2015). Praktik pengasuhan seringkali menjadi sumber stres bagi orang tua (Sari, Krisnatuti, \& Yuliati, 2015). Bagi perempuan, peran sebagai Ibu dapat menjadi sumber stres yang utama karena tanggung jawab besar yang menyertainya (Barnett \& Baruch, 1985). Beberapa studi terdahulu menyebutkan bahwa Ibu mengalami stres pengasuhan yang lebih tinggi dibandingkan ayah (Skreden, 2012); (Widdarson, dkk, 2012). Hal ini disebabkan peran utama Ibu dalam pengasuhan (Kim dan Choi, 2015). Peningkatan stres pengasuhan pada ibu terkait dengan rendahnya tingkat pendidikan, banyaknya jumlah anak, status pernikahan, kurangnya dukungan sosial dan usia Ibu (Asilah \& Hastuti, 2014); (Theule, Wiener, Rogers, \& Marton, 2010).

Stres pengasuhan dapat berdampak negatif terhadap kondisi psikologis anak (Deater-Deckard, 2004); (Neece, 2014); (Gouveia, Carona, Canavarro, dan Moreira, 2016) dan menyebabkan masalah relasi antara anak dan orang tua (Bögels, Lehtonen, \& Restifo, 2010); (Gouveia, dkk 2016). Penelitian terdahulu menunjukkan bahwa stres pengasuhan data mempengaruhi kualitas perilaku pengasuhan, serta perkembangan emosional, fisik dan perilaku anak (DeaterDeckard, 2004)

Lebih jauh, stres pengasuhan dapat membuat orang tua melakukan kekerasan pada anak mereka (Daulay, 2016). Penelitan yang dilakukan oleh Liu dan Wang (2015) menemukan bahwa stres pengasuhan pada ibu memicu agresi psikologis pada Ibu yang kemudian mengarah pada permasalahan perilaku pada anak. Ketidakmampuan orang tua dalam mengelola stres pengasuhan mereka dapat menyebabkan orang tua dengan mudah melakukan kekerasan pada anak yang nantinya akan menimbulkan dampak negatif dalam pembentukan kepribadian anak (Lestari, 2015). Komisi Perlindungan Anak Indonesia (KPAI) menyatakan bahwa terdapat peningkatan kasus kekerasan pada anak setiap tahunnya. Berdasarkan paparan tersebut, dapat disimpulkan bahwa stres pengasuhan tidak hanya mempengaruhi orang tua namun juga mempengaruhi anak.

Stres pengasuhan berkaitan dengan usia anak. Studi yang dilakukan Neece, Green, dan Baker (2012) menemukan bahwa pada pengasuhan anak normal berusia tiga hingga sembilan tahun, stres pengasuhan menurun seiring dengan pertambahan 
usia anak. Dengan kata lain, di masa anak-anak, semakin anak bertambah usia, semakin rendah stres pengasuhan.

Dalam perspektif fase perkembangan, masa anak-anak terbagi menjadifase early childhood, yang dikenal sebagai usia prasekolah dan fase middle childhood, yang dikenal sebagai usia sekolah dasar. Dua fase ini memiliki perbedaan tuntutan pengasuhan. Tuntutan pengasuhan pada anak usia prasekolah bersumber dari kerepotan harian (Crnic, Gaze, dan Hoffman, 2005), belum matangnya perkembangan kognitif (Papalia, Olds, dan Feldman, 2013), kecenderungan mengalami temper loss (Waksclag, dkk, 2012) serta masalah perilaku (Solem, Christophersen, dan Martinussen, 2011). Sementara itu, tuntutan pengasuhan pada anak usia sekolah bersumber dari adanya tuntutan akademik dan meningkatnya tuntutan sosial (Collins, Madsen, \& Susman-Stillman, 2002), serta kerentanan untuk mengalami masalah emosional dan perilaku (Chazan, Davin dan Lavies, 2014).

Menurut United Nations Committee on the Rights of the Child (Oates, 2010), usia prasekolah adalah periode dimana tanggung jawab orang tua berada pada titik terluas dan intens terkait dengan seluruh aspek wellbeing anak, mencakup kehidupan, kesehatan, keamanan fisik dan emosional, pengasuhan, kesempatan belajar dan kebebasan berekspresi. Oleh karena itu, tampak bahwa tanggung jawab pengasuhan di fase ini sangat luas terkait aspek kesejahteraan anak. Dengan besarnya tanggung jawab pengasuhan di fase ini, fase prasekolah dianggap sebagai fase yang krusial yang memicu banyak penelitian terkait pengasuhan pada usia prasekolah, termasuk dalam aspek stres pengasuhan.

Jika fase prasekolah dianggap sebagai fase yang penting, sebaliknya dengan fase perkembangan usia sekolah dasar. Del Giudice (2014) menyatakan bahwa fase perkembangan usia sekolah dasar merupakan fase yang sering "diremehkan" dalam fase perkembangan manusia, padahal fase ini merupakan fase yang krusial dalam perkembangan seorang anak. Mah dan Ford-Jones (2012) bahkan menyebut fase perkembangan usia sekolah dasar sebagai tahun-tahun yang dilupakan (forgotten years) karena kebanyakan penelitian berfokus pada perkembangan anak usia dini dan remaja. Hal ini membuat studi tentang pengasuhan pada anak usia sekolah dasar menjadi penting untuk diteliti lebih lanjut. 
Deater-Deckard (2004) menyatakan bahwa stres pengasuhan terjadi apabila tuntutan peran orang tua tidak terpenuhi dan ketiadaan sumber daya yang mereka miliki untuk menjadi ibu yang baik. Semakin seorang ibu merasakan bahwa mereka tidak dapat menampilkan peran yang diharapkan, semakin mereka merasakan stres pengasuhan. Dengan kata lain, perbedaan tuntutan pengasuhan juga dapat memicu stres pengasuhan.

Rendahnya kemampuan mengelola stres pengasuhan dapat mempengaruhi proses pengasuhan, baik dalam mengasuh anak usia prasekolah maupun anak usia sekolah. Dalam pengasuhan anak usia prasekolah, stres pengasuhan terkait kuat dan signifikan denagn kompetensi sosial usia prasekolah dan memprediksi adaptasi sosial di masa depan (Dubois-Comtois, Moss, Cyr, \& Pascuzzo, 2013). Lebih jauh, Saputra, Yunibhand, dan Sukratul (2016) menemukan bahwa stres pengasuhan yang dialami ibu berkaitan dengan masalah kesehatan mental pada anak usia sekolah dasar. Dengan kata lain, stres pengasuhan, baik dalam pengasuhan anak usia prasekolah maupun anak usia sekolah, dapat menimbulkan dampak buruk perkembangan anak. Hal ini membuat studi tentang stres pengasuhan yang dialami ibu yang mengasuh anak usia prasekolah dan anak usia sekolah dasar menjadi diperlukan.

Neece, dkk (2012) menemukan bahwa stres pengasuhan akan menurun seiring usia di masa anak-anak. Sampel yang digunakan dalam studi tersebut adalah orang tua di Amerika Serikat. Lantas, bagaimana dengan orang tua dengan latar budaya ketimuran seperti Indoneia? Hal ini menarik untuk diteliti lebih lanjut mengingat budaya dapat mempengaruhi kondisi stres yang dialami seseorang (Deater-Deckard, 2004). Lebih jauh, budaya juga mempengaruhi perkembangan peran Ibu yang dapat menjadi sumber stres pengasuhan (Liu, Chen, Yeh, \& Hsieh, 2011). Oleh karena itu, hipotesis yang diajukan dalam penelitian ini adalah terdapat perbedaan stress pengasuhan antara Ibu yang mengasuh anak usia prasekokah dan Ibu yang mengasuh anak usia sekolah dasar. 


\section{Metode}

\section{Desain Penelitian Lokasi dan Waktu}

Penelitian ini menggunakan pendekatan kuantitatif, sejalan dengan tujuan penelitian untuk menguji hipotesis melalui teknik statistik. Desain penelitian yang digunakan adalah cross-sectional study karena pengambilan data dilakukan satu kali. Data dikumpulkan di Jakarta, dari Januari hingga April 2019. Jakarta dipilih sebagai lokasi penelitian karena Jakarta merupakan satu-satunya kota yang mewakili Indonesia sebagai kota yang paling stresdful di dunia (The 2017 Global Least and Most Stressful Cities Ranking).

\section{Teknik Pengambilan Sampel}

Karakteristik sampel yang digunakan dalam penelitian ini adalah Ibu yang terlibat dalam pengasuhan anak dan tinggal di DKI Jakarta. Studi ini melibatkan 124 Ibu yang mengasuh anak usia prasekolah dan 125 Ibu yang mengasuh anak usia sekolah dasar, berusia 21-46 tahun $(\mathrm{M}=34,6, \mathrm{SD}=4,86)$, berasal dari latar belakang pendidikan yang beragam dari Sekolah Dasar hingga Magister, dengan proporsi terbesar adalah lulusan Sekolah Menengah Atas (59\%). Partisipan penelitian ini dipilih melalui teknik convenience sampling. Convenience sampling adalah jenis non-probability sampling dimana anggota populasi yang memenuhi kriteriapraktis tertentu, seperti kemudahan aksesibilitas, kedekatan geografis, ketersediaan waktu serta kesediaan untuk berpartisipasi dilibatkan menjadi partisipan penelitian (Etikan dkk, 2016)

\section{Prosedur pengumpulan Data}

Data yang terkumpul merupakan data primer yang didapatkan melalui kuesioner. Kuesioner berisi data demografis yang meliputi karakteristik ibu dan anak dan skala untuk mengkur stres pengasuhan. Karakteristik ibu meliputi usia ibu dan latar belakang pendidikan Ibu. Karakteristik anak meliputi usia dan jenis kelamin anak. Kuesioner yang disebarkan merupakan kuesioner berbasis kertas, dan partisipan diminta mengisi dengan menggunakan alat tulis. 


\section{Pengukuran dan Penilaian Variabel}

Stres pengasuhan merupakan distress psikologis yang dirasakan oleh orangtua sebagai hasil dari tuntutan peran individu tersebut sebagai orangtua dan membesarkan anak yang ditandai dengan rendahnya emosi positif yang dirasakan oleh orangtua (kebahagiaan, cinta dan rasa senang) dan tingginya emosi negatif yang dirasakan oleh orangtua (perasaan berkorban akan waktu, energi, dan biaya) saat mengasuh anak (Anthony, dkk, 2005); (Berry dan Jones, 1995).

Stres pengasuhan diukur melalui skala Parental Stres Scale (PSS). PSS adalah kuesioner lapor diri yang dikembangkan oleh Berry dan Jones (1995) untuk mengukur stres pengasuhan. PSS memiliki dua komponen, yaitu komponen positif (pleasure) dan komponen negative (strain) yang diturunkan dalam 18 aitem pernyataan. Pada setiap aitem pernyataan, partisipan diminta untuk menilai kesesuaian pernyatan tersebut dengan apa yang dirasakan, dengan lima pilihan respon, yaitu 1 (sangat tidak setuju), 2 (tidak setuju), 3 (netral), 4 (setuju) dan 5 (sangat setuju). Stres pengasuhan dapat dilihat dari skor total responden dari kedua komponen tersebut, semakin tinggi skor total di komponen strain dan semakin rendah skor total di komponen pleasure mengindikasikan tingginya stres pengasuhan. Sebaliknya, semakin rendah skor total komponen strain dan semakin tinggi skor total komponen pleasure mengindikasikan rendahnya stres pengasuhan. PSS yang digunakan dalam penelitian ini telah digunakan dalam penelitian sebelumnya oleh (Amalia \& Kumalasari, 2019;Gani \& Kumalasari, 2019; Kumalasari \& Fourianalistyawati, 2020) dengan indeks reliabilitas sebesar 0,906 yang didapatkan melalui uji reliabilitas konsistensi internal dengan menggunakan Cronbach Alpha.

\section{Analisis Data}

Untuk dapat menguji hipotesis penelitian, analisis data yang digunakan adalah teknik uji beda, yaitu uji T atau uji U. Sebelum melakukan uji beda, terlebih dahulu dilakukan uji asumsi untuk memastikan teknik uji beda yang dapat digunakan. Uji asumsi yang dilakukan adalah uji normalitas. Jika asumsi normalitas terpenuhi, maka teknik uji beda yang digunakan adalah statistik parametrik, yaitu 
Uji T. Sebaliknya, jika asumsi normalitas tidak terpenuhi, maka teknik uji beda yang digunakan adalah statistik non-parametrik, yaitu Uji U.

\section{Hasil dan Pembahasan}

Berdasarkan uji normalitas, diketahui bahwa data yang terkumpul tidak terdistribusi normal $(\mathrm{Z}<0,01)$. Oleh karena itu, teknik uji beda yang dapat digunakan adalah uji U (Mann-Whitney U Technique). Berikut adalah hasil uji U:

\section{Tabel 1}

Mann-whitney test

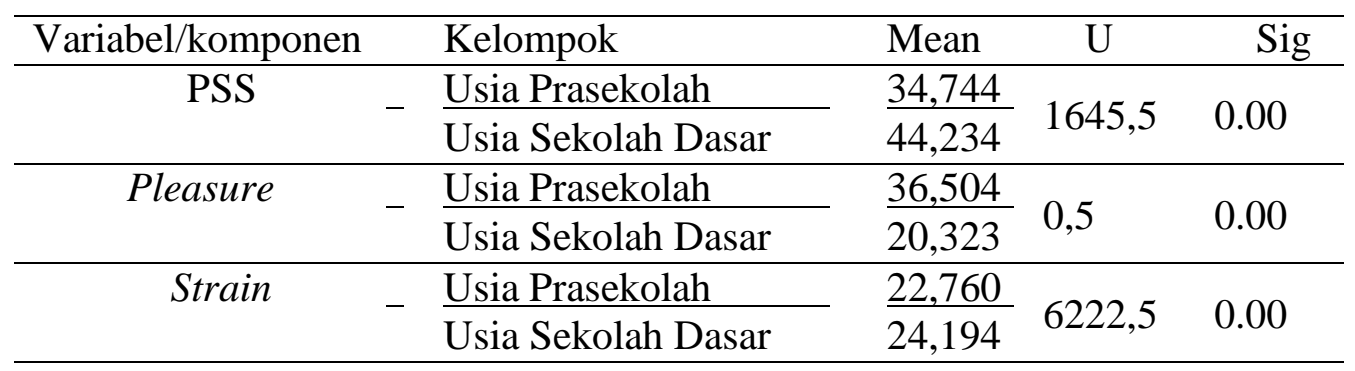

Dari tabel 1, tampak bahwa ibu yang mengasuh anak usia sekolah dasar merasakan komponen pleasure yang lebih rendah dan merasakan komponen strain yang lebih tinggi dibandingkan ibu yang mengasuh anak usia prasekolah. Secara keseluruhan tampak bahwa Ibu yang mengasuh anak usia sekolah dasar mengalami stress pengasuhan yang lebih tinggi dibandingkan Ibu yang mengasuh anak usia prasekolah $(\mathrm{U}=1.645,5, \mathrm{p}<0.05)$

Dari hasil tersebut, dapat dimaknai bahwa Ibu yang mengasuh anak usia sekolah dasar cenderung lebih terbebani akan kegiatan pengasuhan anak dan merasa bahwa anak merupakan sumber stres dalam hidup mereka, sebaliknya ibu yang mengasuh anak usia prasekolah merasa bahwa anak merupakan sumberkasih sayang dalam hidup mereka. Selain itu, ibu yang mengasuh anak usia sekolah dasar memiliki lebih banyak kekhawatiran dalam mengasuh anak mereka, sebaliknya ibu yang mengasuh anak usia prasekolah lebih optimis dalam mengasuh anak mereka. Dalam mengevaluasi peran pengasuhan, Ibu yang mengasuh anak usia prasekolah lebih merasakan kebahagiaan dalam pengasuhan dibandingkan Ibu yang mengasuh anak usia sekolah dasar. 


\section{Pembahasan}

Hasil dari penelitian ini menunjukkan bahwa terdapat perbedaan stres pengasuhan antara ibu yang mengasuh anak usia prasekolah dan anak usia sekolah dasar. Lebih lanjut, penelitian ini juga menunjukkan bahwa pada sampel di DKI Jakarta, stres pengasuhan yang dialami ibu yang mengasuh anak usia sekolah dasar lebih tinggi daripada ibu yang mengasuh anak usia prasekolah. Hal ini bertentangan dengan temuan Neece dkk., (2012) yang menunjukkan bahwa stres pengasuhan akan menurun seiring bertambahnya usia anak.

Perbedaan temuan dalam penelitian ini diperkirakan karena adanya perbedaan sampel penelitian. Penelitian yang dilakukan (Neece dkk, 2012) melibatkan sampel orang tua yang mengasuh anak dengan keterlambatan perkembangan, sementara itu penelitian ini melibatkan sampel orang tua yang mengasuh anak dengan perkembangan normal. Perbedaan sampel penelitian ini memungkinkan adanya dinamika stress pengasuhan yang juga berbeda. Dalam mengasuh anak dengan keterlambatan perkembangan, stres pengasuhan akan menurun seiring dengan perkembangan anak dalam keterampilan hidup sehari-hari yang memungkinkan mereka menampilkan perilaku yang diharapkan orang tua (Neece dkk, 2012).

Lebih lanjut, perbedaan temuan penelitian juga diperkirakan karena adanya perbedaan budaya dari sampel yang diteliti. Studi yang dilakukan Neece, dkk (2012) menggunakan sampel di Amerika Serikat yang merepresentasikan budaya barat. Bornstein (2013) menyatakan bahwa budaya mempengaruhi ekspektasi orang tua terhadap anak. Studi yang dilakukan Stevenson dan Lee (2002) menemukan bahwa orang tua dari Asia memiliki ekspektasi akademik yang lebih tinggi dibandingkan dengan orang tua di Amerika Serikat. Lebih lanjut, Ibu di Amerika Serikat cenderung untuk menilai prestasi sebagai refleksi dari kemampuan yang mereka miliki, sementara itu Ibu di Asia menekankan pada pentingnya kerja keras untuk mencapai prestasi akademik. Ekspektasi tersebut memiliki implikasi terhadap penilaian orang tua terhadap anak mereka, yang pada gilirannya dapat mempengaruhi stres pengasuhan yang mereka alami (Deater dan Deckard, 2004).

Dalam penelitian ini, ibu yang mengasuh anak usia sekolah ditemukan merasakan sedikit emosi positif dalam pengasuhan dibandingkan ibu yang 
mengasuh anak usia prasekolah. Hal ini dimungkinkan karena semakin besar seorang anak, semakin besar pula ekspektasi orang tua terkait kepatuhan dan kontrol diri anak (Deater dan Deckard, 2004). Mengenai kepatuhan, anak usia prasekolah berada pada fase perkembangan moralitas pra konvensional, dimana pada fase ini anak mematuhi perintah hanya untuk menghindari hukuman atau mendapatkan hadiah. Hal ini sejalan dengan praktik pengasuhan yang umum terjadi di Indonesia. Koentjaraningrat (dalam Sumargi, Sofronoff, dan Morawska, 2015) menyatakan bahwa orang tua di Indonesia terbiasa mendisiplinkan anak mereka dengan memberikan hukuman atau menjanjikan hadiah. Praktik pengasuhan semacam ini dapat sesuai pada anak usia prasekolah, namun tidak pada anak usia sekolah dasar.

Anak usia sekolah dasar berada pada fase perkembangan kognitif konkret operasional, dimana mereka mampu mengembangkan pemikiran logis. Perkembangan fungsi kognitif ini membuat orang tua perlu untuk memberikan penjelasan yang lebih kompleks dan menarik agar anak mematuhi apa yang dikatakan orang tua, berbeda dengan fase sebelumnya dimana orang tua membuat anak patuh dengan cara mendistraksi anak, memberikan ancaman hukuman atau menjanjikan hadiah (Sumargi, dkk, 2015). Di sisi lain, orang tua anak usia sekolah dasar mengembangkan harapan mereka terkait kepatuhan dan kontrol diri anak seiring dengan perkembangan usia (Deater dan Deckard, 2004). Kondisi ini dapat menyebabkan stres pengasuhan yang dimiliki ibu yang mengasuh anak usia sekolah dasar lebih tinggi daripada ibu yang mengasuh anak usia prasekolah.

Studi ini juga menemukan bahwa ibu yang mengasuh anak usia sekolah dasar merasakan lebih banyak emosi negatif dalam pengasuhan dibanding ibu yang mengasuh anak usia prasekolah. Hal ini dimungkinkan karena peran orang tua meningkat terkait keterlibatan mereka dalam memfasilitasi kegiatan sekolah anak (Collins,dkk, 2002). Pada usia sekolah dasar, anak memiliki tuntutan akademik yang lebih tinggi dibandingkan prasekolah (Sotardi, 2017). Pada usia sekolah dasar, anak harus mampu untuk menguasai keterampilan akademik seperti membaca, menulis dan berhitung. Hal ini membuat orang tua perlu memperhatikan pembelajaran yang dilakukan anak dan memastikan anak menguasai keterampilan tersebut. Untuk melakukan pengawasan tentang kegiatan anak di sekolah, orang tua 
juga biasanya melakukan usaha lebih untuk berinteraksi dengan guru dan orang dewasa yang bertanggung jawab di sekolah. Hal ini menjadi tugas baru yang menantang bagi orang tua. Tugas tambahan orang tua seringkali dikeluhkan oleh orang tua yang merasa terganggu dengan tugas sekolah anak. Tantangan pengasuhan ini yang memungkinkan stres pengasuhan yang dialami ibu yang mengasuh anak usia sekolah dasar lebih tiggi daripada ibu yang mengasuh anak usia dasar.

Lebih lanjut, seiring dengan meningkatnya regulasi diri anak, orang tua mengembangkan harapan bahwa anak menjadi lebih mandiri dan bertanggung jawab dalam melakukan tugas mereka di sekolah dan di rumah (Del Giudice, 2014). Namun di sisi lain, anak usia sekolah juga rentan untuk mengalami kesulitan emosional dan perilaku (Chazan, dkk, 2014). Kondisi yang bertolak belakang ini dapat membuat ibu harus melakukan usaha keras agar anak dapat memenuhi ekspektasi sekaligus lebih kooperatif.

Lebih jauh, anak usia sekolah berada pada fase pra-remaja. Sejumlah studi menemukan bahwa orang tua yang mengasuh anak pra-remaja memiliki stres pengasuhan yang lebih tinggi dibandingkan fase sebelumnya (Deater dan Deckard, 2004). Anak usia sekolah juga secara umum lebih rentan terhadap sumber stres. Selain itu, anak pada usa ini sering berkata bahwa konflik mereka dengan orang tua karena orang tua tidak menyediakan bantuan yang cukup atau orang tua hanya menghabiskan sedikit waktu dengan mereka (Bornstein, 2002). Dengan kata lain, pada fase pra-remaja, perilaku anak menjadi lebih menantang. Hal ini diperkuat oleh temuan Neece, dkk (2012) yang menemukan bahwa masalah perilaku pada anak dan stres pengasuhan saling terkait.

\section{Kesimpulan dan Saran}

Berdasarkan paparan di atas, dapat disimpulkan bahwa ibu yang mengasuh anak usia sekolah dasar mengalami stres pengasuhan yang lebih tinggi dibandingkan ibu yang mengasuh anak usia prasekolah. Hasil ini terkait dengan perbedaan karakteristik fase perkembangan, tuntutan pengasuhan dan juga ekspektasi pengasuhan antara usia prasekolah dan usia sekolah dasar. Dari hasil penelitian ini, tampak bahwa pengasuhan anak usia sekolah dasar tidak bisa 
diremehkan. Ibu yang mengasuh anak usia sekolah dasar perlu dibekali pengetahuan dan keterampilan agar dapat mengelola stres pengasuhan yang dimilikinya.

Namun demikian, paparan di atas hanya berdasarkan tinjauan teoretis, bukan studi empirik. Hal ini karena penelitian ini hanya fokus pada perbedaan stres pengasuhan, dan tidak mengukur variabel lain seperti budaya, keyakinan pengasuhan, harapan ibu dan variabel terkait lain. Untuk dapat mengidentifikasi penyebab stres pengasuhan ibu yang mengasuh anak usia sekolah dasar lebih tinggi dibandingkan anak usia prasekolah, studi lebih lanjut diperlukan dengan melibatkan variabel terkait budaya. Lebih lanjut, untuk melihat dinamika stres pengasuhan, studi longitulinal disarankan.

\section{Daftar Pustaka}

Amalia, P. M., \& Kumalasari, D. (2019). Openness To Expericene, Conscientiousness, Extraversion, Agreeableness, Neuroticism: Manakah Yang Terkait Dengan Mindful Parenting? Intuisi: Jurnal Psikologi Ilmiah, 11(2), 158-167.

Asilah \& Hastuti, D. (2014). Hubungan Tingkat Stres Ibu dan Pengasuhan Penerimaan Penolakan dengan Konsep Diri Remaja pada Keluarga Bercerai. Jurnal Ilmu Keluarga dan Konsumen, 7(1), 10-18. Doi: 10.24156/jikk.2014.7.1.10

Barnett, R. C., \& Baruch, G. K. (1985). Women's involvement in multiple roles and psychological distres. Journal of Personality and Social Psychology, 49(1), 135-145. https://doi.org/10.1037/0022-3514.49.1.135

Bemmelen, S, T. (2015). State of the wolrd's father country repport: Jakarta (ID): Men Care+

Berry, J. D, \& Jones, W. H. (1995). The Parental Stres Scale : initial psychometric evidence. Journal of Social and Personal Relationships, 12(3), 463 - 472. Doi: 10.1177/0265407595123009

Bögels, S., Lehtonen A., \& Restifo, K. (2010). Mindful parenting in mental health care. Mindfulness, 1(2), 107-120. Doi:0.1007/s12671-010-0014-5

Bornstein, M.H. (2002). Handbook of Parenting (Vol 1): Children and Parenting. New Jersey(US): Lawrence Erlbaum Associates, Publisher.

Bornstein, M. H. (2013). Parenting and child mental health: a crossculturalperspective. World Psychiatry, 12(3), 258-

265.Doi: 10.1002/wps.20071 
Chazan, M., Laing, A.F., \& Davies, D. (2014).Emotional and Behavioural Difficulties in Middle Childhood: Identification, Assessment and Intervention in School. New York(US): Routledge.

Collins, W. A., Madsen, S. D., \&Susman-Stillman, A. (2002). Parenting during middle childhood. In M. H. Bornstein (Ed.), Handbook of Parenting (Vol 1): Children and Parenting. New Jersey(US): Lawrence Erlbaum Associates, Publisher.

Crnic, K.A., Gaze, C. and Hoffman, C. (2005). Cumulative Parenting Stres across the Preschool Period: Relations to Maternal Parenting and Child Behaviour at Age 5. Infant and Child Development, 14(2), 117-132. Doi: 10.1002/icd.384 
Daulay, N. (2016). Kajian psikologi lintas budaya tentang stres pengasuhan pada ibu. Jurnal Tarbiyah, 2(23), 296-323. Doi: 10.30829/tar.v23i2.115

Deater-Deckard, K. (2004). Parenting Stres. London(UK): Yale University Press.

Del Giudice, M. (2014). Middle childhood: an evolutionary-developmental synthesis. Child Development Perspectives, 8(4), 1-8. Doi: 10.1111/cdep. 12084

Dubois-Comtois, K., Moss, E., Cyr, C., \& Pascuzzo, K. (2013). Behavior Problems in Middle Childhood: The Predictive Role of Maternal Distres, Child Attachment, and Mother-Child Interactions. Journal of Abnormal Child Psychology, 41(8), 1311-1324. doi:10.1007/s10802-013-9764-6

Etikan, I., Musa, S.A., Alkassim, R.S (2016). Comparison of convenience sampling and purposive sampling. American Journal of Theoretical and Applied Statistics, 5 (1), 1-4. doi: 10.11648/j.ajtas.20160501.11

Feizi, A., Najmi, B., Salesi, A., Chorami, M., \& Hoveidafar, R. (2014).Parenting stres among mothers of children with different physical, mental, and psychological problems.Journal of research in medical sciences : the official journal of Isfahan University of Medical Sciences, 19(2), 145-152. PubMed PMID: 24778669

Gani, I.A., \& Kumalasari,D. (2019). Be Mindful, Less Stress : Studi tentang mindful parenting dan stres pengasuhan pada ibu dari anak usia middle childhood di Jakarta. Jurnal Psikologi, 15(2), 98-107. doi:10.24014/ jp.v14i2.7744

Gouveia, M. J., Carona, C., Canavarro, M. C., \& Moreira, H. (2016). Self compassionanddispositional mindfulness are associated withparenting styles and parenting stres: the mediating role of mindfulparenting. Mindfulness, 7(3), 700-712.doi: 10.1007/s12671-016-0507-y

Kim, K., \& Choi, J. (2015). Sources of Parenting stres for Mothers and Fathers of Young Children. Indian Journal of Science and Technology, 8(35). Doi: 10.17485/ijst/2015/v8i35/85

Kumalasari, D., \& Fourianalistyawati, E. (2020). The role of mindful to the parenting stress in mothers with children at early age. Jurnal Psikologi, 19(2), 135-142. https://doi.org/10.14710/jp.19.2.135-142

Lestari, S. (2012). Psikologi Keluarga : Penanaman Nilai \& Penanganan Konflik dalam Keluarga. Jakarta(ID): Kencana Prenamedia Group.

Liu, C., Chen, Y., Yeh, Y., \& Hsieh, Y. (2011) Effects of maternal confidence and competence on maternal parenting stres in newborn care. Journal of 
Advanced Nursing,68(4), $\quad 908-918 . \quad$ Doi: $\quad 10.1111 / \mathrm{j} .1365-$ 2648.2011.05796.x

Liu, L., \& Wang, M. (2015). Parenting stres and children's problem behavior in China: The mediating role of parental psychological aggression. Journal of Family Psychology, 29(1), 20-28. https://doi.org/10.1037/fam0000047

Mah, VK., \& Ford-Jones, L. (2012). Spotlight on middle childhood: Rejuvenating the 'forgotten years'. Paediatrics \& Child Health, 17(2), 81-83. Doi:10.1093/pch/17.2.81

Neece, C. L., Green, S. A., \& Baker, B. L. (2012). Parenting stress and child behavior problems: A transactional relationship across time. American Journal on Intellectual and Developmental Disabilities, 117(1), 48-66. https://doi.org/10.1352/1944-7558-117.1.48

Oates, John ed. (2010). Supporting Parenting. Early Childhood in Focus, 5. Milton Keynes (UK): The Open University

Papalia, D.E., Olds, S.W., \& Feldman, R.D. (2013). Human Development. New York(US): McGraw-Hill

Pinquart, M. (2017). Parenting stres in caregivers of children with chronicphysical condition - a meta-analysis. Stres and Health,34(2), 1-11. Doi: 10.1002/smi.2780

Saputra, F., Yunibhand, J., \& Sukratul, S. (2016). Relationship between personal, maternal and familial factors with mental health problems in school-aged children in Aceh Province, Indonesia.Asian Journal of Psychiatry, 25(1), 207-212.Doi: 10.1016/j.ajp.2016.10.025.

Sari, D.Y., Krisnatuti, D., \& Yuliati, L.N. (2015). Stres Ibu dalam Mengasuh Anak pada Keluarga dengan Anak Pertama Berusia di Bawah Dua Tahun. Jurnal Ilmu Keluarga dan Konsumen, 8(2), 80-87. Doi: 10.24156/jikk.2015.8.2.80

Skreden, M., Skari, H., Malt, U. F., Pripp, A. H., Björk, M. D., Faugli, A., \& Emblem, R. (2012). Parenting stres and emotional wellbeing in mothers and fathers of preschool children. Scandinavian Journal of Public Health, 40(7), 596-604. doi:10.1177/1403494812460347

Solem, M.-B., Christophersen, K.-A., \& Martinussen, M. (2011). Predicting parenting stres: children's behavioural problems and parents' coping. Infant and Child Development, 20(2), 162-180. doi:10.1002/icd.681

Sotardi, V.A. (2017). Exploring school stress in middle childhood: interpretations, experiences, and coping. Pastoral Care in Education, 35(1), 13-27. DOI: 10.1080/02643944.2016.1269360 
Stevenson, H. W., \& Lee, S.Y. (1990).Context of achievement.Monographs of the Society for Research in Child Development, 55(1-2), 1-7. doi:10.1111/j.1540-5834.1990.tb00260.x

Sumargi, A., Sofronoff, K. \& Morawska, A. (2015). Understanding Parenting Practices and Parents' Views of Parenting Programs: A Survey Among Indonesian Parents Residing in Indonesia and Australia. J Child Fam Stud,24(1), 141-160. Doi: 10.1007/s 10826-013-9821-3

Theule, J., Wiener, J., Rogers, M. A., \& Marton, I. (2010). Predicting Parenting Stres in Families of Children with ADHD: Parent and Contextual Factors. Journal of Child and Family Studies, 20(5), 640-647. doi:10.1007/s10826010-9439-7

Wakschlag, L.S., Henry D.B., Tolan P.H., Carter A.S., Burns J.L., Briggs-Gowan, M.J. (2012). Putting theory to the test: modeling a multidimensional, developmentally-based approach to preschool disruptive behavior. Journal of the American Academy of Child and Adolescent Psychiatry, 51(6), 593604

Widarsson, M., Engström, G., Rosenblad, A., Kerstis, B., Edlund, B., \& Lundberg, P. (2013). Parental stres in early parenthood among mothers and fathers in sweden. Scandinavian Journal of Caring Sciences, 27(41), 839-847. doi: 10.1111/j.1471-6712.2012.01088.x

Zelman, J. J., \& Ferro, M. A. (2018). The parental stres scale: psychometric properties in families of children with chronic health conditions. Interdisciplinary Journal of Applied Family Studies, 1-13.Doi: 10.1111/fare. 12306 